\title{
Association of GGCX gene polymorphism with warfarin dose in atrial fibrillation population in Xinjiang
}

Xiayizha Kamali, Muhuyati Wulasihan*, Yu-Chun Yang, Wu-Hong Lu, Zhi-Qiang Liu and Peng-Yi He

\begin{abstract}
Objective: To study the effects of $\gamma$-glutamyl carboxylase (GGCX) rs2592551 polymorphism on warfarin dose in atrial fibrillation patients in Xinjiang region.

Methods: Polymerase chain reaction - restriction fragment length polymorphism and direct sequencing methods were used to detect the rs2592551 genotype in 269 atrial fibrillation patients with warfarin administration. The effects of different genotypes on warfarin dose were statistically analyzed.

Results: The rs 2592551 polymorphism detection results were 136 cases of wild-type homozygous CC genotype (50.56\%), 115 cases of heterozygous CT genotype (42.75\%), 18 cases of homozygous $\Pi$ genotype (6.69\%). The allele frequency C was $71.93 \%$, T was $28.07 \%$. The stable warfarin dose average was $2.86 \pm 0.61 \mathrm{mg} / \mathrm{d}$ in patients with CC genotype, $3.59 \pm 0.93 \mathrm{mg} / \mathrm{d}$ in patients with CT genotype and $4.06 \pm 0.88 \mathrm{mg} / \mathrm{d}$ in patients with $\Pi$ genotype. The warfarin dose in different genotypes were compared, there was statistically significant difference between CC and $\Pi$, $C C$ and $C T(P<0.05)$, but the $T$ and $C T$ showed no significant difference $(P>0.05)$.

Conclusion: In atrial fibrillation population in Xinjiang, patients with CT and TT genotypes in GGCX gene rs259251 loci required for significantly higher warfarin dose than those with CC genotype. Therefore, rs2592551 polymorphism may one of the factors affecting the warfarin dose in patients with atrial fibrillation.
\end{abstract}

Keywords: GGCX gene, Atrial fibrillation, Gene polymorphism, Warfarin

\section{Introduction}

Atrial fibrillation (AF) is the most common sustained clinical arrhythmia, the overall incidence of atrial fibrillation was $0.4 \%$. The incidence of atrial fibrillation increased with age, it can reach up to $10 \%$ in people over 75 years. The increased prevalence of atrial fibrillation was also associated with increased prevalence of coronary heart disease, hypertension, heart failure and other diseases. In the next 50 years, the atrial fibrillation will become one of the most popular cardiovascular disease.

Thromboembolism, particular the cerebral embolism was currently the complication with highest morbidity and mortality caused by atrial fibrillation. A retrospective survey of the hospitalized cases of atrial fibrillation in some areas showed that the prevalence of stroke was $17.5 \%$ in patients with atrial fibrillation [1]. Many studies showed that the ischemic stroke and complications will greatly

* Correspondence: muhuyati@163.com

Department of Cardiology, First Affiliated Hospital of Xinjiang Medical University, Urumqi 830011, P.R. China increase in atrial fibrillation patients who did not receive the anticoagulant therapy. Therefore, in order to reduce the risk of stroke in atrial fibrillation patients, the timely active anticoagulant was essential in clinical treatment [2].

During atrial fibrillation, the systolic function loss and long-term heart rate increaseing will lead to heart failure and increased mortality to 2 times than healthy people [3]. There were racial differences in atrial fibrillation causes and risk factors according to the previous study $[4,5]$. $\gamma$-glutamyl carboxylase (GGCX) was the major enzyme affecting the metabolism of warfarin. Warfarin is the most commonly used anticoagulant in clinical treatment, and GGCX is one of the candidate genes in individual differences of response to warfarin [6-10]. In this study, polymerase chain reaction, restriction fragment length polymorphism and direct sequencing were used to genotype the rs2592551 polymorphism in GGCX gene to, analyze the relation between gene polymorphism and warfarin dose in patients with atrial fibrillation. 


\section{Results and discussion}

The distribution of GGCX gene rs2592551 was in line with Hardy-Weinberg equilibrium $(P>0.05)$.

In general clinical data comparison: Age, smoking, and blood urea nitrogen showed significant differences between men and women $(P<0.05$, Table 1$)$, and the other indicators showed no difference $(P>0.05)$.

As shown in Table 2, There was statistically significant difference between CC and TT, CC and CT $(P<0.05)$ in warfarin dose, but there was not difference between TT and CT genotype $(P>0$. 05).

$\gamma$-glutamyl carboxylase (GGCX) can catalyze the $\gamma$ carboxylating effects of clotting factor II, VII, IX, X. Its role was dependent on vitamin $\mathrm{K}$ and Oxygen $\left(\mathrm{O}_{2}\right)$ [11]. When reduced vitamin $\mathrm{K}$ and $\mathrm{O}_{2}$ existed, GGCX incorporated $\mathrm{CO}_{2}$ specifically into glutamic acid residues, the $\gamma$ carboxylated glutamic acid were produced. The vitamin $\mathrm{K} 2$, 3 - epoxide was also produced [12,13]. Glutamic acid residue containing vitamin K-dependent clotting factor II, VII, IX, $\mathrm{X}$, protein $\mathrm{C}$ and protein $\mathrm{S}$ should be carboxylated by GGCX to acquire the activity. Then a series of cascades happened to cause blood coagulation. Therefore, GGCX was major enzyme affecting the metabolism of warfarin [14-20].

Atrial fibrillation is the most common arrhythmia in clinical practice, which can cause the high morbidity and mortality, but the cause and pathogenesis are still unclear [21].

Table 1 Comparison of the clinical data between male and female

\begin{tabular}{|c|c|c|c|c|}
\hline Parameters & Men & Women & $\mathrm{x}^{2}$ or $t$ & $P$ value \\
\hline Age (Year) & $59.03 \pm 14.34$ & $54.60 \pm 14.81$ & 2.48 & $<0.05$ \\
\hline Smoking $(n, \%)$ & $51(33.77)$ & $24(20.33)$ & 5.95 & $<0.05$ \\
\hline Alcohol $(n, \%)$ & $31(20.53)$ & $15(12.71)$ & 2.86 & 0.10 \\
\hline BMI (kg/m2) & $24.09 \pm 3.08$ & $24.35 \pm 3.13$ & -0.69 & 0.50 \\
\hline Height (Cm) & $166.34 \pm 7.64$ & $165.86 \pm 8.37$ & 0.48 & 0.63 \\
\hline Weight (kg) & $69.41 \pm 13.56$ & $67.40 \pm 12.58$ & 1.24 & 0.22 \\
\hline Hypertension (n,\%) & $84(55.63)$ & $61(51.69)$ & 0.41 & 0.54 \\
\hline $\operatorname{CAD}(n, \%)$ & $87(57.62)$ & $64(54.24)$ & 0.31 & 0.62 \\
\hline $\mathrm{DM}(\mathrm{n}, \%)$ & $83(54.97)$ & $55(46.61)$ & 1.85 & 0.18 \\
\hline $\operatorname{SBP}(n, \%)$ & $119.34 \pm 18.79$ & $116.99 \pm 14.70$ & 1.12 & 0.27 \\
\hline $\operatorname{DBP}(n, \%)$ & $71.40 \pm 11.32$ & $73.01 \pm 10.84$ & -1.18 & 0.24 \\
\hline TG $(n, \%)$ & $1.41 \pm 0.98$ & $1.28 \pm 0.70$ & 1.16 & 0.25 \\
\hline TC $(n, \%)$ & $4.10 \pm 0.96$ & $4.23 \pm 1.04$ & -1.04 & 0.30 \\
\hline HDL-C (n,\%) & $0.97 \pm 0.31$ & $0.94 \pm 0.30$ & 0.62 & 0.54 \\
\hline LDL-C (n,\%) & $2.46 \pm 0.79$ & $2.49 \pm 0.73$ & -0.41 & 0.68 \\
\hline FBG $(n, \%)$ & $6.07 \pm 1.97$ & $5.95 \pm 1.95$ & 0.48 & 0.64 \\
\hline BUN (n,\%) & $342.59 \pm 109.03$ & $303.69 \pm 86.08$ & 3.18 & $<0.00$ \\
\hline
\end{tabular}

(BMI: body mass index; SBP: systolic blood pressure; DBP: diastolic blood pressure; TG: triglycerides; TC: total cholesterol; HDL-C: high-density lipoprotein; LDL-C: low-density lipoprotein; FBG: fasting blood glucose; BUN: blood urea nitrogen).
Table 2 Genotype frequencies, warfarin dose and its comparison in rs2592551 of GGCX gene

\begin{tabular}{lccccc}
\hline $\mathbf{N}$ (269) & & $\mathbf{N}(\mathbf{\%})$ & $\begin{array}{c}\text { Warfarin } \\
\text { dose }(\mathbf{m g} / \mathbf{d})\end{array}$ & U value & P value \\
\hline rs2592551 & CC & $136(50.56)$ & $2.86 \pm 0.61$ & & \\
genotype & & & & & \\
& CT & $115(42.75)$ & $3.59 \pm 0.93$ & & \\
TT & $18(6.69)$ & $4.06 \pm 0.88$ & & \\
CC vs TT & & & 353.00 & $<0.000$ \\
CT vs TT & & & 746.00 & 0.057 \\
CC vs CT & & & 4232.00 & $<0.000$ \\
C & $387(71.93)$ & & \\
T & $151(28.07)$ & & & \\
\hline
\end{tabular}

Xinjiang is a multi-ethnic co-populated area, and the main ethnic groups are Han, Uygur, Kazak, Hui, Kirgiz, Mongolian, Tajik, etc. Due to geographical conditions, living, eating habits in various ethnic groups and genetic background in Xinjiang, there were obvious differences between these minor ethnicities and Han population in other areas. Up to date, although several studies have been reported the relation between GGCX gene polymorphisms and warfarin dose, there was no study reporting the effect of GGCX gene polymorphisms on Warfarin dose in atrial fibrillation patients in Xinjiang. The previous studies indicated that GGCX gene polymorphism had different degrees of impact on warfarin dose. It has been considered as the major genetic factor influencing warfarin dose.

In this study, we found the stable warfarin dose average was $2.86 \pm 0.61 \mathrm{mg} / \mathrm{d}$ in patients with CC genotype, $3.59 \pm 0.93 \mathrm{mg} / \mathrm{d}$ in patients with CT genotype and $4.06 \pm 0.88 \mathrm{mg} / \mathrm{d}$ in patients with TT genotype. This results indicated that the TT genotype carriers in atrial fibrillation population in Xinjiang required higher dose of warfarin than patients with CC genotype, which was to say, the full mutation genotype required more warfarin than the wild homozygotes genotype. The CT and TT genotypes required warfarin dose which had no significant different. There was no significant difference on warfarin dose between heterozygous (part mutant) genotype and full mutation genotype.

In conclusion, GGCX gene polymorphism may be one of the factors affecting the dose of warfarin in patients with atrial fibrillation in Xinjiang. However, the results

Table 3 The loci, primer sequences, annealing temperature and the product length of amplified gene

\begin{tabular}{lccc}
\hline Gene locus & $\begin{array}{c}\text { Primer } \\
\text { sequences }\left(\mathbf{5}^{\prime}-\mathbf{3}^{\prime}\right)\end{array}$ & $\begin{array}{c}\text { Annealing } \\
\text { temperature }\left({ }^{\circ} \mathbf{C}\right)\end{array}$ & $\begin{array}{c}\text { Product } \\
\text { length (bp) }\end{array}$ \\
\hline rs2592551 & $\begin{array}{l}\text { GGACTTAGAAA } \\
\text { GGAACGGATGA }\end{array}$ & 61.2 & 381 \\
& CTTGAGAAAAG & & \\
& GCAAAGCAGAC & & \\
\hline
\end{tabular}



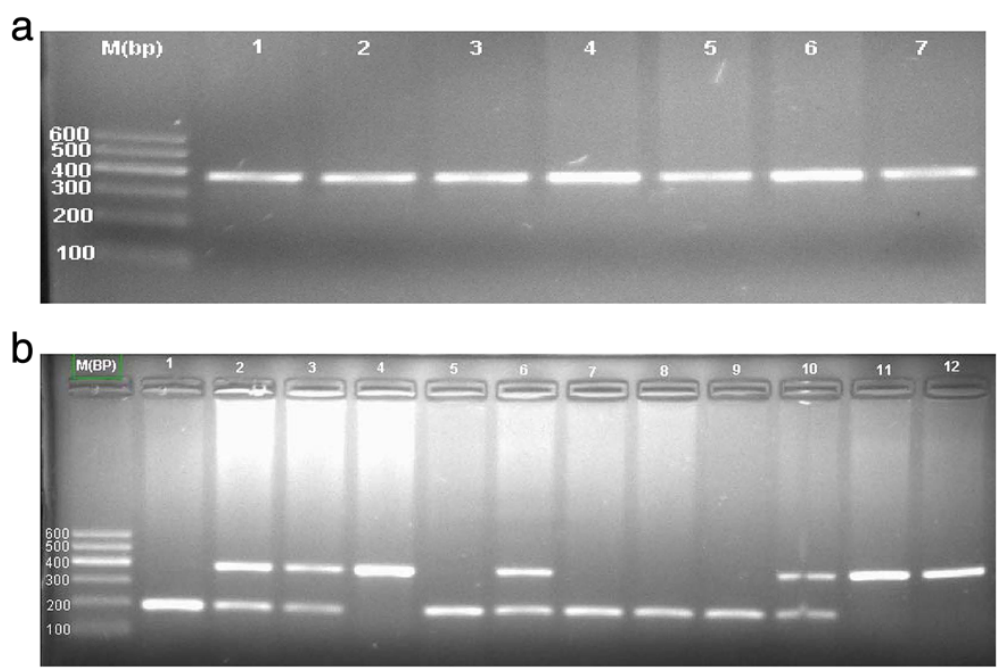

Figure 1 The PCR and digestion products of rs2592551. a: rs2592551 PCR product with product length of 381 bp; b: rs 2592551 digestion products. 2 , 3, 6, 10 were heterozygous $\subset$ genotype. 1, 5, 7, 8, 9 were mutated homozygous TT genotype. 4, 7, 8, 9 were homozygous CC wild-type (Due to the 189 and $192 \mathrm{bp}$ enzyme digestion lengths were very close to each other, there showed overlap on the electropherogram showing as one band).

need to be further confirmed in a larger sample and different populations.

\section{Subjects and methods}

\section{Subjects}

From January 2009 to December 2012, the inpatients and outpatients with atrial fibrillation were selected in the First Affiliated Hospital of Xinjiang Medical
University. The atrial fibrillation was confirmed by ECG or Holter monitoring, the patients with familial history, valvular heart disease, congenital heart disease and lung disease were excluded. 269 atrial fibrillation patients including 131 Han population, 83 of Kazak, 53 of Uygur, 1 of Kirgiz, 1 of Mongolian were enrolled. 118 patients were female with age from 25 to 89 years $(54.60 \pm 14.81)$ And 151 patients were male with age from 22 to 89 years

a

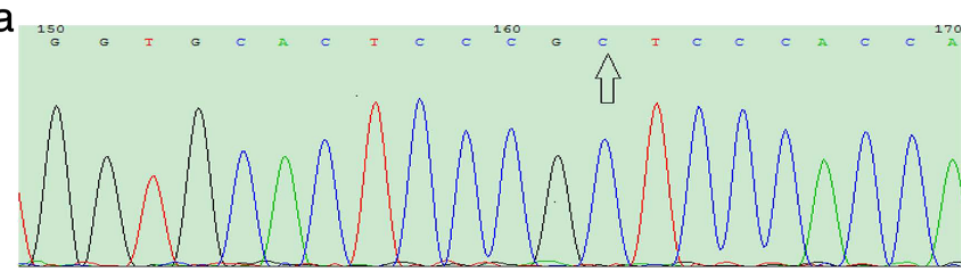

b

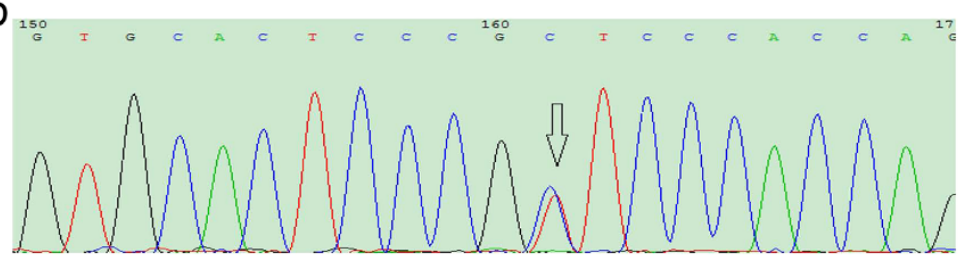

C

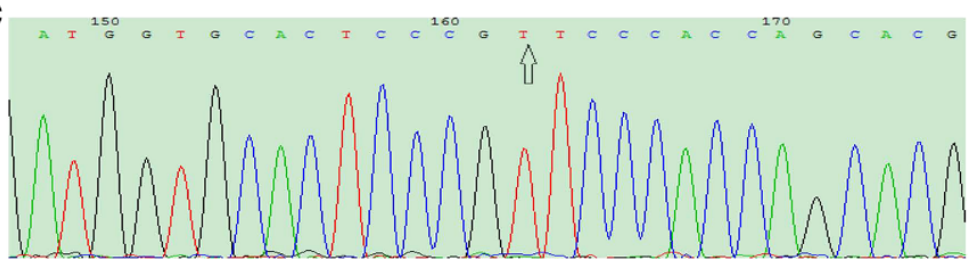

Figure 2 The sequence of $\mathrm{CC}, \mathrm{CT}$, and $\mathrm{TT}$ genotype, the arrow showed the mutation (a: $\mathrm{CC}, \mathrm{b}: \mathrm{CT}, \mathrm{c:} \mathrm{TT})$. 
$(59.03 \pm 14.34)$. Clinical data included age, gender, height, weight, recent warfarin dosage, International normalized ratio (INR) values, and drug administration.

Stable warfarin dose: With the same dose, the 2 consecutive INR values in patients were between $1.8 \sim 3.0$, the separated time between 2 times of detection should be at least more than $7 \mathrm{~d}$ [21]. All patients did not have bleeding or embolic symptoms.

Exclusion criteria: The patients with blood diseases, coagulation disorders, liver and kidney dysfunction, severe infection, severe heart failure, anemia, cancer and drugs or food administration which had effects on warfarin doses were exclude from this study. The protocol was approved by Medical Ethics Committee of First Affiliated Hospital of Xinjiang medical university and all the patients signed written informed consent.

\section{Methods}

\section{Clinical data}

The height, weight were measured by specialized personnel, past history and living habits were obtained through questionnaires. Body mass index $(\mathrm{BMI})=$ weight $/$ height ${ }^{2}\left(\mathrm{~kg} / \mathrm{m}^{2}\right)$.

\section{Blood biochemical indicators tests}

Serum total cholesterol (TC), high density lipoprotein cholesterol (HDL-C), low density lipoprotein cholesterol (LDL-C), triglycerides (TG), uric acid, fasting blood glucose (FBG), blood urea nitrogen, serum creatinine and other biochemical indicators were measured by inspection center of the First affiliated hospital of Xinjiang Medical University. All blood samples were taken in the morning fasting state.

\section{DNA extraction and PCR amplification}

$5 \mathrm{ml}$ of fasting venous blood were obtained. After adequate anticoagulation, they were stored at $-80^{\circ} \mathrm{C}$. The DNA was extracted by using the whole blood genome extraction kit (TIANGEN Ltd.) Primers were designed using Primer premier 5.0 software and were synthesized by Shanghai Sangon Biological Engineering Co., Ltd. The primers sequence was shown in Table 3. PCR amplification was performed in C1000TM Thermal CyclerPCR instrument. $20 \mu \mathrm{l}$ of PCR reaction system contained $10 \mu \mathrm{l}$ of PCR Master mix (2×), 0.5 pmol of upstream and downstream primers, $7.5 \mu \mathrm{l}$ of $\mathrm{ddH}_{2} \mathrm{O}$, and $2 \mu \mathrm{l}$ of genomic DNA. Cycling parameters were as follows: $95^{\circ} \mathrm{C}$ denaturation for $3 \mathrm{~min}, 95^{\circ} \mathrm{C}$ deformation for $30 \mathrm{~s}, 61.2^{\circ} \mathrm{C}$ annealing for $30 \mathrm{~s}, 72^{\circ} \mathrm{C}$ extension for $1 \mathrm{~min}$, a total of 35 cycles were include, total extension at $72^{\circ} \mathrm{C}$ for $5 \mathrm{~min}$.

\section{Genotyping}

Polymerase chain reaction-restriction fragment length polymorphism and direct sequencing methods were used to genotype. The rs2592551 changed from $\mathrm{C}$ to $\mathrm{T}$ and one MbiI (BsrBI) restriction endonuclease was created. After Mbi digestion, there were two fragments of $189 \mathrm{bp}$ and $192 \mathrm{bp}$. C allele had no restriction sites and remained a $381 \mathrm{bp}$ fragment. Therefore, the CC genotype was wild type homozygous and was only one band with fragment length of $381 \mathrm{bp}$. CT genotype was heterozygous mutation, which was part mutation and had three fragments of 381,189 and $192 \mathrm{bp}$, respectively. Because the $189 \mathrm{bp}$ and $192 \mathrm{bp}$ was very close and the bands were overlapped each other, we only can see that CT heterozygous had two fragments and TT homozygous had one band (Figure 1).

\section{Sequencing}

10 of CC type, CT type, and TT type in rs2592551 of GGCX type gene were randomly selected, respectively, for sequencing by Shanghai Sangon Biological Engineering Co., Ltd. The direct sequencing confirmed these genotypes (Figure 2).

\section{Statistical methods}

SPSS17.0 statistical package was used for statistical analysis. The gene counting method was used for allele frequency and genotype frequencies calculation. Each genotype and allele frequencies were calculated, the categorical variables were expressed as percentages. The matching degree of Hardy-Wrinberg genetic equilibrium in our subjects was tested with Chi-square. The warfarin dose between different gender and genotype were compared using rank sum test namely as $U$ test. $P<0.05$ was considered as statistically significant.

\section{Abbreviations}

TG: Triglycerides; TC: Total cholesterol; HDL-C: High-density lipoprotein; LDL-C: Lowdensity lipoprotein; GGCX: $ү$-glutamyl carboxylase; FBG: Fasting blood glucose.

\section{Competing interests}

The authors declare that they have no competing interests.

\section{Authors' contributions}

$\mathrm{XK}$ and $\mathrm{M}$ carried out the molecular genetic studies and drafted the manuscript. YCY and WHL carried out the genotyping. ZQL and PYH participated in the design of the study and performed the statistical analysis. WHL conceived of the study, and participated in its design and coordination and helped to draft the manuscript. All authors read and approved the final manuscript.

\section{Acknowledgments}

This work was funded by Key Project of Scientific research for Institutions of Higher Education of Xinjiang Uygur Autonomous Region (XJEDU2011/30), and National Natural Science Foundation of China (81060017).

Received: 4 October 2013 Accepted: 18 October 2013

Published: 23 October 2013

\section{References}

1. China Cardiovascular Association: Retrospective survey of hospitalized patients with atrial fibrillation in some areas of China. Zhonghua Xin Xue Guan Bing Za Zhi 2003:913-916.

2. Barrios V, Escobar C: New evidences for old concerns with oral anticoagulation in atrial fibrillation: focus on dabigatran. Expert Opin Pharmacother 2012, 13:2649-2661. 
3. Manolis AJ, Kallistratos MS, Poulimenos LE: Recent clinical trials in atrial fibrillation in hypertensive patients. Curr Hypertens Rep 2012, 14:350-359.

4. Huang SW, Xiang DK, Huang L, Chen BL, An BQ, Li GF, Luo ZY: Influence of GGCX genotype on warfarin dose requirements in Chinese patients. Thromb Res 2011, 127:131-134.

5. Chen LY, Eriksson N, Gwilliam R, Bentley D, Deloukas P, Wadelius M: Gamma-glutamyl carboxylase (GGCX) microsatellite and warfarin dosing. Blood 2005, 106:3673-3674.

6. Shuen AY, Wong BY, Fu L, Selby R, Cole DE: Evaluation of the warfarinresistance polymorphism, VKORC1 Asp36Tyr, and its effect on dosage algorithms in a genetically heterogeneous anticoagulant clinic. Clin Biochem 2012, 45:397-401.

7. Yang L, Ge W, Yu F, Zhu H: Impact of VKORC1 gene polymorphism on interindividual and interethnic warfarin dosage requirement-a systematic review and meta analysis. Thromb Res 2010, 125:e159-e166.

8. Rai AJ, Udar N, Saad R, Fleisher M: A multiplex assay for detecting genetic variations in CYP2C9, VKORC1, and GGCX involved in warfarin metabolism. Clin Chem 2009, 55:823-826.

9. Suriapranata IM, Tjong WY, Wang T, Utama A, Raharjo SB, Yuniadi Y, Tai SS: Genetic factors associated with patient-specific warfarin dose in ethnic Indonesians. BMC Med Genet 2011, 12:80.

10. Scott SA, Patel M, Martis S, Lubitz SA, van der Zee S, Yoo C, Edelmann L, Halperin $J$, Desnick RJ: Copy number variation and warfarin dosing: evaluation of CYP2C9, VKORC1, CYP4F2. GGCX and CALU. Pharmacogenomics. 2012, 13:297-307.

11. Yang J, Chen Y, Li X, Wei X, Chen X, Zhang L, Zhang Y, Xu Q, Wang H, Li Y, Lu C, Chen W, Zeng C, Yin T: Influence of CYP2C9 and VKORC1 genotypes on the risk of hemorrhagic complications in warfarin-treated patients: A systematic review and meta-analysis. Int J Cardiol 2013. doi:pii: S0167-5273 (13)01362-4. doi:10.1016/j.ijcard.2013.07.151.

12. Crosier MD, Peter I, Booth SL, Bennett G, Dawson-Hughes B, Ordovas JM: Association of Sequence Variations in Vitamin K Epoxide Reductase and y-Glutamyl Carboxylase Genes with Biochemical Measures of Vitamin K Status. J Nutr Sci Vitaminol (Tokyo) 2009, 55:112-119.

13. Stafford DW: The vitamin K cycle. J Thromb Haemost 2005, 3:1873-1878.

14. Kimura R, Miyashita K, Kokubo Y, Akaiwa Y, Otsubo R, Nagatsuka K, Otsuki T, Okayama A, Minematsu K, Naritomi H, Honda S, Tomoike H, Miyata T: Genotypes of vitamin $\mathrm{K}$ epoxide reductase, gamma-glutamyl carboxylase, and cytochrome P450 2C9 as determinants of daily warfarin dose in Japanese patients. Thromb Res 2007, 120:181-186.

15. Stromich JJ, Weber AK, Mirzaei YR, Caldwell MD, Lewis DE: New adjuvants to enhance anticoagulant activity of warfarin. Bioorg Med Chem Lett 2010, 20:1928-1932.

16. Vanakker OM, De Coen $K$, Costrop L, Coucke PJ, Vanhaesebrouck P, De Paepe A: Functional polymorphism in gamma-glutamylcarboxylase is a risk factor for severe neonatal hemorrhage. J Pediatr 2011, 159:347-349.

17. Wadelius M, Chen LY, Downes K, Ghori J, Hunt S, Eriksson N, Wallerman O, Melhus H, Wadelius C, Bentley D, Deloukas P: Common VKORC1 and GGCX polymorphisms associated with warfarin dose. Pharmacogenomics J 2005, 5:262-270.

18. Rieder MJ, Reiner AP, Rettie AE: Gamma-glutamyl carboxylase (GGCX) tagSNPs have limited utility for predicting warfarin maintenance dose. J Thromb Haemost 2007, 5:2227-2234

19. Weston BW, Monahan PE: Familial deficiency of vitamin K-dependent clotting factors. Haemophilia 2008, 14:1209-1213.

20. Schelleman H, Brensinger CM, Chen J, Finkelman BS, Rieder MJ, Kimmel SE: New genetic variant that might improve warfarin dose prediction in African Americans. Br J Clin Pharmacol 2010, 70:393-399.

21. D'Andrea G, D'Ambrosio R, Margaglione M: Oral anticoagulants: Pharmacogenetics Relationship between genetic and non-genetic factors. Blood Rev 2008, 22:127-140. doi:10.1016/j.blre.2007.11.004.

doi:10.1186/1476-511X-12-149

Cite this article as: Kamali et al:: Association of GGCX gene polymorphism with warfarin dose in atrial fibrillation population in Xinjiang. Lipids in Health and Disease 2013 12:149.

\section{Submit your next manuscript to BioMed Central and take full advantage of:}

- Convenient online submission

- Thorough peer review

- No space constraints or color figure charges

- Immediate publication on acceptance

- Inclusion in PubMed, CAS, Scopus and Google Scholar

- Research which is freely available for redistribution

Submit your manuscript at www.biomedcentral.com/submit
C Biomed Central 